\title{
Materia en el dolor usada. La poesía de Francisco Alonso Ruiz
}

\section{Materia en el dolor usada. The poetry of Francisco Alonso Ruiz \\ Matéria na dor usada. A poesía de Francisco Alonso Ruiz}

\author{
Manuel Valero Gómez ${ }^{1}$ \\ ${ }^{1}$ Doctor Filología Hispánica \\ Cómo citar este artículo en edición digital: Valero-Gómez, M. (2019). Materia en el dolor usada. La \\ poesía de Francisco Alonso Ruiz. Cultura de los Cuidados (Edición digital), 23 (54). Recuperado de \\ http://dx.doi.org/10.14198/cuid.2019.54.09 \\ Correspondencia: Avda. Los Girasoles, n.ํㅜ 7. San Vicente del Raspeig (Alicante) 03690 \\ Correo electrónico de contacto: manuelvalerogomez@gmail.com \\ Recibido: 28/03/2019; Aceptado: 12/05/2019
}

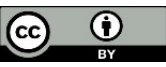

\section{ABSTRACT}

Although little known, the poetic career of Alicantine Francisco Alonso Ruiz Pérez (1948-2018) establishes -decisively-a bridge between two shores that seem irreconcilable for the genre in the city of Alicante: the brilliant and splendid first postwar promotion of poets Alicante and those generations closer in time. In any case, his recent and surprising death has made the ordination and study of a work that exceeds half a century dedicated to cultural activity more urgent. Take into account his evident textual drama, anonymity between provincial bohemianism and lag regarding any generational horde. The following article aims to identify some visible signs of what we might call poetic.

Keywords: Francisco Alonso Ruiz, poetry of Alicante, Alicante, Testimonio de tiempo.

\section{RESUMO}

Embora pouco conhecida, a carreira poética de Alicantine Francisco Alonso Ruiz
Pérez (1948-2018) estabelece decisivamente- uma ponte entre duas margens que parecem irreconciliáveis para o gênero na cidade de Alicante: a brilhante e esplêndida promoção dos poetas no pósguerra Alicante e as gerações mais próximas no tempo. Em todo caso, sua recente e surpreendente morte tornou mais urgente a ordenação e o estudo de uma obra que excede meio século dedicada à atividade cultural. Leve em conta seu evidente drama textual, o anonimato entre o boêmio e o hiato provinciano em relação a qualquer horda geracional. $\mathrm{O}$ artigo a seguir tem como objetivo identificar alguns sinais visíveis do que poderíamos chamar de poético.

Palavras chave: Francisco Alonso Ruiz, poesia de Alicante, Alicante, Testemunho do tempo.

\section{RESUMEN}

Aunque poca conocida, la trayectoria poética del alicantino Francisco Alonso Ruiz 
Pérez (1948-2018) establece -decisivamenteun puente entre dos orillas que parecen irreconciliables para el género en la ciudad de Alicante: la brillante y esplendorosa primera promoción de poetas de la posguerra alicantina y aquellas generaciones más próximas en el tiempo. En todo caso, su reciente y sorpresivo fallecimiento ha hecho más urgente la ordenación y el estudio de una obra que rebasa más de medio siglo dedicado a la actividad cultural. Ténganse en cuenta su evidente drama textual, anonimato entre la bohemia provinciana y desfase respecto a cualquier horda generacional. El siguiente artículo pretende identificar algunos signos visibles de aquello que podríamos denominar poética.

Palabras clave: Francisco Alonso Ruiz, poesía alicantina, Alicante, Testimonio de tiempo.

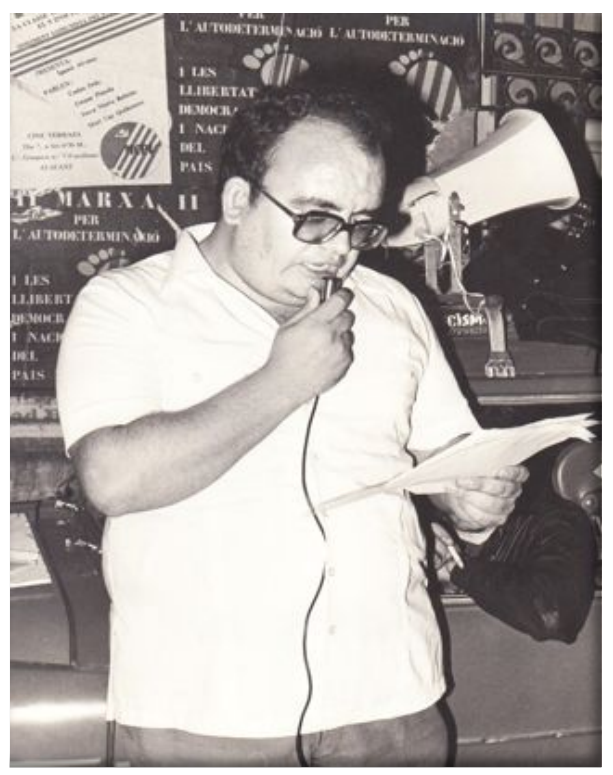

\section{INTRODUCCIÓN}

Aunque poca conocida, la trayectoria poética del alicantino Francisco Alonso Ruiz Pérez (1948-2018) establece -decisivamenteun puente entre dos orillas que parecen irreconciliables para el género en la ciudad de Alicante: la brillante y esplendorosa primera promoción de poetas de la posguerra alicantina (Valero Gómez, 2018) y aquellas generaciones más próximas en el tiempo. En todo caso, su reciente y sorpresivo fallecimiento ha hecho más urgente la ordenación y el estudio de una obra que rebasa más de medio siglo dedicado a la actividad cultural. Ténganse en cuenta su evidente drama textual, anonimato entre la bohemia provinciana y desfase respecto a cualquier horda generacional. En todo caso, y a tenor de lo que ya hemos dicho en otros lugares sobre Alonso Ruiz, podemos identificar algunos signos visibles de aquello que podríamos denominar poética.

La realidad como objeto anímico, aquella pieza que hemos denominado como el gran logro ético-estético en los textos del poeta alicantino, explica tanto las tensiones que ponen en práctica la poesía alonsiana como las matizaciones conceptuales que dan cuenta de su recorrido. Dicho esto, puede citarse un conjunto de topoi literarios (lluvia, sombra, muerte, silencio y día/tarde/noche) que no deja de advertir los vaivenes y resoluciones de su escritura. Esta visión de la cotidianidad objetivada mediante una metafísica profundamente sentimental está imbricada con el espacio. Hacemos referencia al desarrollo que se sucede en su producción: un repliegue a la intimidad que va de la mano de la dialéctica naturalezaciudad-casa mundo (Valero Gómez, 2012, 9).

En todo caso, esta problemática no se desengaña del nódulo central de todo su historial: el lacerado peso de la existencia, ese acento humano que desde sus inicios le marca a fuego. Solo que Alonso Ruiz dedica 
toda su obra a ese humano esfuerzo con la pretensión de que precisamente ese asunto y ese esfuerzo sean encubiertos, pasen desapercibidos. Pero si bien este rasgo puebla todos y cada uno de los poemas de Alonso Ruiz, con indiferencia del cariz que tengan (desde el costumbrismo alegre y local hasta los laudatorios y el tema fogueril o festero), el lirismo, ese signo que Salinas (1970: 34-45) ve como unitario para todo el género del $X X$, sigue destacando para aquellos lectores iniciados en la poesía de Alonso. Ese autodidactismo que tanto sorprendió a Vicente Mojica, uno de sus más representativos guías, refleja su aprendizaje de la poesía española más contemporánea. Y a su vez, pone de relevancia cómo se va conformando esa realidad como objeto anímico, cómo esos topoi anteriormente citados adquieren nuevas connotaciones según se prolonga su escritura.

\section{DESARROLLO DEL TEMA}

Por iniciar nuestra explicación por uno de ellos, daremos comienzo mediante el dolor y la muerte, quizá los términos más complejos de su poesía. Si hay un libro o ciclo poético en el que esté más presente el tema de la muerte ese es Acento humano (1969). El libro arranca con tres sonetos demoledores y un verso que es toda una declaración de intenciones: "marcado por la muerte, lucho y vivo". El poeta inicia su andadura lírica con un poemario dominado por un estadio psicológico que le conduce a la angustia y el sufrimiento, cuando no a la desesperación. El hecho es que los poemas no aluden en ningún momento a lugar físico alguno, sino que términos como vida, muerte, dolor, lucha o cansancio pueblan todas sus páginas. Entre sus versos se puede leer que tiene "miedo a la muerte y a la vida", que "hay que morir un poco cada día" y "más no puedo callar, porque me grita / el dolor en las venas". Más allá de alguna cita explícita a León Felipe o Miguel Hernández, se denota cierto pesimismo unamuniano que conecta directamente con la poesía tremendista y existencial de los años cuarenta gracias a imágenes como la caída y el abismo (Valero Gómez, 2013: 18-19).

Yendo un paso hacia delante, Testimonio de tiempo (1982) representa la instauración del yo poético en el medio natural. Tal es así que, pese a ser un libro dominado por el dolor ante el fallecimiento del padre, predomina una visión ingenua que alumbra la aflicción romántica y la interiorización simbolista. Así pues, poco tienen que ver el dolor y la muerte de Acento humano con Testimonio de tiempo, puesto que la precisión y el culto a la belleza modernistas se entremezclan con el filosofismo obsesivo de Salvador Rueda (Carnero, 1985: 86) o la visión trascendente de Antonio Machado. Ahora, a la altura de los años ochenta, el dolor se goza y la muerte se sucede. El gozo del instante se detiene en la emoción. Aparecen la luz y el ámbito rural. La musicalidad se adueña del ritmo y se observa una vocación depurativa que si bien no precisa desnudar la idea, al menos convoca su equilibrio con la forma. Poemas como "Melancolía" dejan ver que el yo poético ha salido de la angustia existencial y se encuentra en mitad del espacio natural. Los espacios abiertos como el mar ("Sonetos al mar"), la plaza y el pueblo ("Cosas viejas" o "La panadera") conforman una atmósfera agreste. Figuras como el silencio y el día, la tarde o la noche poseen ahora una profundidad luminosa, alejada del lacerado oscurismo de Acento humano y de la tensión reflexiva del posterior Soledad de alma (2001). Como decimos, el sujeto poético se ha liberado del corsé religioso y ya no supone un impedimento a su canto límpido. 
Respecto al citado Soledad de alma, nos da pie para comentar otros topoi recurrentes en la poesía de Alonso Ruiz. El libro comienza con unos versos muy significativos ("Abres la puerta y se mira el mar. / Cierras la puerta y queda dentro el ruido / de las olas, el furioso oleaje"), puesto que si bien Testimonio de tiempo representa la exteriorización del yo poético, ahora el poeta inicia un repliegue que -pasando por la muerte de su madre en Soledad de alma y el posterior espacio urbano- se extenderá hasta la casa-mundo de sus últimos poemas. El poeta ha alcanzado una madurez asombrosa gracias a una frialdad templada y reflexiva, muy lejana del fervor de Acento humano (1969). Este repliegue es progresivo y desigual a la par que se produce en sentidos diversos: por un lado, el propiamente físico (de la naturaleza y la ciudad a la casa-mundo); y por otro lado, el intelectual y sentimental, donde el yo poético proyecta el estado anímico de una realidad. Por ejemplo, si nos detenemos un segundo en esa serie de poemas sueltos que Paco publica incesantemente entre los años que separan Soledad de alma (2001) y Cuaderno de ahora mismo (2012), nos daremos de bruces no solo con la ciudad, sino con una asimilación afectiva de la ciudad. $\mathrm{Y}$ a partir de aquí, se incorporan dos símbolos (la lluvia y la sombra) al universo alonsiano que hasta ahora habían estado presentes en él, pero con una importancia que no alcanzaba el significado interno que tienen en este momento. La cuestión es que toda la poesía de Francisco Alonso Ruiz trata de una impostura, trata de resolver un enigma del cual sabe la respuesta y no puede huir. Quisiéramos tomar el poema "Cosas terribles" como un resumen de su planteamiento ético-estético:

Hasta saber que somos lo que existe: una materia en el dolor usada, una verdad que muere con nosotros un firmamento sobre nuestras ansias, la desesperación que nos consume y la esperanza y la desesperanza el juego ciego, el llanto y el olvido que es la existencia humana.

(Ruiz, 2015: 30)

Y entenderá el lector que esta intimidad que ha invadido el orbe lírico de Alonso no se limita a esa "forma natural de existencia de la esfera de la esencia", sino que se levanta "por encima de lo meramente humano, tanto de la masa cuanto de los propios instintos" (Lukács, 1975: 311). La cuestión es que ni existe un "lugar vacío donde se anuncia la afirmación impersonal" (Blanchot, 1969: 49) como tampoco dejamos en manos del dogma humanista la afirmación de un individuo mediante la escritura. No es nada nuevo, si nos atenemos a la relación que siempre ha existido entre arte y vida social (Plejanov, 1974: 21). Francisco se cuestiona desde el primer momento que el reflejo del mundo externo en la conciencia humana (Lukács, 1970: 48), su realidad como objeto anímico, se encuentra viciado en tanto que todos nacemos condicionados por una realidadpráctica ideológica. $\mathrm{Y}$ al igualar esta tesis con la existencia misma, el poeta se desengaña de ese viejo axioma de la vida haciéndose en la escritura, sino más bien que la vida ya está hecha de antemano: de ahí ese soberbio verso que condensa toda su poética, somos materia en el dolor usada. En todo caso, cabe preguntarse quiénes nos hacen sufrir a diario (aquello de los índices bursátiles, el parqué y la usura) en este «Mundo Libre» globalizado en el que nos ha tocado vivir, mientras hay quien todavía finge buscarse al otro lado del discurso. A este lado del dolor, acaso el único, la “esperanza y la 
desesperanza", "el juego ciego, el llanto y el olvido".

\section{La fantasmagoría subjetivista o el libro de la vida}

El valor simbólico de los topoi especificados varía según se asienta un cambio en el desarrollo anímico-geográfico de la ética-estética alonsiana hasta la consumación de la dialéctica naturalezaciudad-casa mundo. Igual que en el ejemplo de una obra literaria concreta, una trayectoria literaria adquiere su sentido en la cuestión que ella debe resolver (Macherey, 1974: 26). Es decir, la crítica historicista estudia la evolución de un recorrido literario, pero no logra explicarlo (Rodríguez, 1974: 180-181): no estudia al autor como una forma histórica determinada, sino como categoría general bajo el "signo de una necesidad" (Macherey, 1974: 41). Y esta forma de explotación -que según Bourdieu (2005: 45) no deja de ser una forma de racismo- no hace más que reproducir el horizonte burgués, entreverado por la esencialidad de la fenomenología y la aspiración romántica de una subjetividad trascendental. Así pues, como señala Lucien Goldmann a la hora de condensar su estructuralismo genético, el concepto clave no es la conciencia real, sino la conciencia posible.

En cualquier caso se trata de vencer la servidumbre de la literatura, el espesor de la historia que "la nueva positividad de las ciencias de la vida, del lenguaje y de la economía", quizá perfeccionada por el capitalismo avanzado, encuentra su "correspondencia con la instauración de una filosofía trascendental" (Foucault, 1971: 239). Poco más habrá que insistir en la imposibilidad de una esencia para la literatura (Eagleton, 2013: 39), porque, ni mucho menos, su estudio nos conduce al estudio de ese hombre esencializado, engrandecido hasta la virtud divina de la creación. Como si el sujeto literario pudiera desertar de sí mismo, de las garras de su ensoñación de libertad y autorrealización (conciencia real), a no ser que derribe el muro de la violencia ideológica y del individualismo histórico (conciencia posible). Por lo tanto, la consecuencia práctica de esta manera impostada de afrontar el acontecimiento de la literatura (Eagleton, 2013), lejos de la objetividad material de esta, se limita al ámbito biográfico-historicista como respuesta al "universo del discurso" (Jakobson, 1983: 29) y una "sensación de universo" (Valéry, 1990: 137) que llega hasta nosotros bajo la engañosa promesa del estilo.

Y el estilo "siempre tiene algo en bruto", "es una forma sin objetivo, el producto de un empuje, no de una intención" (Barthes, 2005: 19). Esta visión del mundo que es el estilo posee la funcionalidad de responder $-y$ al mismo tiempo de ser signo visible- a una supuesta representación de esa subjetividad. Y así es como la ideología lleva a cabo su secreta tarea de reproducción: mediante el texto el sujeto se hace sujeto, la individualidad se hace individualidad, la historia se hace historia y la ideología se hace ideología. Existe, qué duda cabe, la urgencia de separarse de la "imaginación creadora", "hay pues que volverse hacia lo invisible dentro de la libertad poética", "para alcanzar en su noche el origen ciego de la obra" (Derrida, 1989: 16). Y más que nunca, la opacidad de aquello que conocemos como escritura, "se hunde en su propia representación" (92) en tanto en cuanto "el texto se plantea en lo real que lo engendra" -que lo reproduce, valdría la pena matizarhasta "hundirse en una fantasmagoría subjetivista" (Kristeva, 1978: 10). Ahora no parece tan inocente la afirmación de Paul 
Valéry (1990: 118) cuando señala que la "ejecución del poema es el poema".

La cuestión es que resulta difícil imaginar el lenguaje como "condición de toda subversión y de toda creatividad" (Mayos, 1995: 117), “liberación" -si llevamos al extremo, al fin y al cabo, el lenguaje como casa del ser heideggeriano- "del gran silencio de la materia" (Steiner, 1982: 63). Esta fantasmagoría subjetivista es la representación más evidente $-\mathrm{y}$ tenebrosa, al mismo tiempo- de que, para este idealismo como para toda la problemática kantiana, "sólo en la acción moral individual se manifiesta el espíritu -puro-" (Rodríguez, 1973: 50). Lejos queda ya, en consecuencia, una imagen esencial así como un creativismo funcional para el lenguaje. Dicho voluntarismo estético, tal y como se denomina esta "acción moral individual" o "hecho esencializado" (Rodríguez, 1973: 50), pone coto a la frágil linealidad que sostiene su necesidad en el estudio de cualquier historial literario. De ahí que, ya en el terreno poético, entendamos ese voluntarismo estético como vitalismo poético, uno de los pilares fundamentales para entender la poesía moderna (Friedrich, 1974), ya que supone la fusión entre poesía y vida, un salvoconducto para aproximar los opuestos kantianos de lo trascendental y lo empírico, el alma y la vida (Rodríguez y Salvador, 1987: 164-165). Y que, al mismo tiempo, se desdobla en la contradicción entre lenguaje $y$ pensamiento $o$ entre lenguaje $y$ fondo oscuro del alma (Rodríguez, 1994: 38). Todo ello implica que para cada producción textual, entendiendo como tal que existe forzosamente un ejecutor de esa práctica-ideológica concreta, ese conjunto de necesidades que el evolucionismo historicista persigue deben ser entendidas como signos visibles o calas de las condiciones objetivas de producción por un sujeto específico. Por estos motivos, las "referencias" del estilo se hallan en el nivel de una "biología" o de un "pasado", no de una "Historia" (Barthes, 2005: 19): y aquí, la "cosa" del escritor, "su esplendor y su prisión, su soledad" (19). Porque el ser humano no puede insertar su "libertad de escritor en la opacidad de la lengua, porque a través de ella, está toda la Historia, completa y unida al modo de una Naturaleza" (Barthes, 2005: 18) en tanto en cuanto, esa misma Naturaleza, atañe directamente a un objeto artificial que no deja ser un invento de su afán por alcanzar la individualidad histórica.

Y quizá, la realidad como objeto anímico y el repliegue a la intimidad son las principales calas de producción a la hora de objetivar la poesía de Francisco Alonso. De hecho, puede observarse en su vastísima producción poética una línea temática que no solo cuestiona y reflexiona en torno a la existencia (esa impostura, ese tema encubierto que la sobrevuela), sino que pone en cuestión la propia escritura, su ficcionalidad y servidumbre. Hablamos de una serie de poemas, contados con los dedos de las dos manos, que relaciona la vida con los márgenes de la escritura. Porque si bien el voluntarismo poético alonsiano está imbricado en cada uno de sus textos, de tal manera que supone -para el mismo poetala resolución de una problematización (nuevamente la necesidad) de la literatura; en estos contados textos, decimos, se vislumbra una distancia estética entre la triada sujeto/autor/escritura-vida. La muestra más evidente es el poema titulado "El libro", publicado en una antología colectiva en 2009:

Hay alguien en la mesa de un despacho, en un lugar que ignoro, y hay en la mesa un libro 
con caracteres góticos.

Todo en la estancia cobra un grave peso de angustia en sus contornos, una sombra de signos y de letras escritas en un tiempo muy remoto.

(Ruiz, 2009: 30)

El poeta alicantino, gran conocedor -por otra parte- de la Biblia y mejor estudioso de las religiones, accede a esa humanidad del lenguaje (Lafont, 1993: 246) que la tradición occidental ha depositado en la escritura como un "medio legítimo de fijar las reglas y estatutos para la convivencia humana que Dios-Moisés ha ofrecido al hombre en forma de legislación de valor eterno" (Wahnón, 1995: 27). Evidentemente, el tema de esta composición forma parte de aquello que Dámaso Alonso denomina trasmundo del poeta. $\mathrm{O}$ desciendo al caso de Alonso Ruiz, denota dos severas consecuencias: a) la definitiva superación del plano religioso y, quizá, existencialismo más tremendista; b) debido a la aceptación del ser humano como condición finita, fuera ya de la angustia dirigida a Dios (Acento humano) o la frustración (Soledad de alma). Aquí se respira la atmósfera que impregna toda la poesía escrita por el poeta alicantino a partir del siglo nuevo, donde la soledad terrenal se ralentiza gracias a la reflexión y el entendimiento. Solo que, en este poema en concreto, va más allá e incluso se burla de la concepción que aún mantenemos sobre un posible creador o la Muerte misma:

En la última página se ve

toda una relación de nombres. Todos tachados, salvo el mío, que es el último, y que yo veo expuesto ante mis ojos.

Alguien, a quien se llama Muerte, viste de negro, y usa lentes de arduo plomo, y a nadie dice nada. Sólo escribe, en libro con epígrafes de oro, cómo se llama cada ser humano al nacer. $\mathrm{Y}$ al pasar un tiempo, corto o largo, que eso nunca está medido, en el códice de los caracteres góticos traza una raya roja sobre el nombre que estaba manuscrito.

(Ruiz, 2009: 30)

Alonso Ruiz plantea ingeniosamente esta superposición entre literatura y vida mediante la metáfora del libro de la vida, gracias a esa problemática que liga íntimamente el lenguaje y la tradición judeocristiana de la Creación. Si como bien se sabe el texto marca sus propios límites, abre su discurso poniendo en juego una pieza fundamental (el deslinde entre sujeto $y$ autor):

Desconozco

dónde se encuentra el libro inenarrable de la existencia, el libro prodigioso de la muerte y la vida. Sólo entiendo que es el nombre, trascrito con decoro, el de alguien que va a morir un día y que puedo ser yo, Francisco Alonso.

(Ruiz, 2009: 30)

Francisco Alonso ha conducido al lector, sin este apenas sospecharlo, al callejón sin salida de la subjetividad. O mejor todavía, la representación de este libro de la vida significa escenificar todo el espesor ideológico de la historia, significa tomar el rábano por las hojas y salir airoso de la individualidad histórica pegando un portazo a la fantasmagoría de la subjetividad. Por estos motivos, el poeta simula esta manera óntica de entender el discurso (Heidegger, 2009: 81), como expresión y articulación significante de la comprensibilidad de estar en el mundo (181). Es decir, como el voluntarismo estético que ofrece al escritor ese señuelo del estilo, una visión de mundo que no resulta más que expresar yo-soy-libre. En todo caso, 
Alonso Ruiz toma a broma la lectura literal del libro de la vida como toma a broma los entresijos historiográficos de la fortuna literaria y se anula como individualidad histórica, como autor finalmente. La cuestión es que -como puede verse en otro poema de idéntico tema, aquel titulado "Mundo múltiple" y con reminiscencias borgianas- la conceptualización sobre la idea humanista del autor es un mero espejismo, acaso un reflejo falaz. Como señala Derrida (1989: 22), "si la escritura es inaugural, no es porque cree, sino por una cierta libertad absoluta" de "hacer surgir lo ya-ahí en su signo", "libertad de respuesta que reconoce como único horizonte el mundo-historia y la palabra que solo puede decir: el ser ha comenzado ya desde siempre". El libro de la vida de Alonso Ruiz cuestiona el voluntarismo estético que la literatura esconde. Un círculo en la arena. Una rayuela de tiza dibujada sobre los adoquines: allí donde la individualidad histórica promete al escritor una «tarea para sí mismo», allí donde el lenguaje promete al escritor una «tarea para sí mismo». "No hay más que un Libro, y es el mismo Libro que se distribuye en todos los libros" (Derrida, 1989: 19). El escritor como vasallo de la literatura.

\section{Querer el mismo afán que nos devora: Voluntarismo estético y condicionalidad de la poesía}

En cualquier caso, estos topoi literarios que hemos visto como arquetipos fundamentales de ese artefacto estilístico denominado realidad anímica esconden un gran riesgo. $\mathrm{O}$ mejor dicho, todo este andamiaje estético corre el riesgo de (mal)entenderse como un severo pleonasmo. De algún modo, el historial literario de Francisco Alonso siempre nos remite a las mismas lagunas $y$ problemáticas, al mismo punto de partida. El desorden textual del poeta alicantino -no nos cansaremos de insistir en esta deudaimposibilita, o en todo caso dificulta hasta el extremo, el reconocimiento y el estudio crítico de su recorrido, ya que sus cincuenta años de tarea literaria no han sido pagados sino con la moneda de la indiferencia. Así, el historial literario de Alonso Ruiz se presenta de manera fragmentaria, propio -por ejemplo- de la poesía lírica, incluyendo un margen para la alternancia e incluso la contradicción. Si bien hemos identificado la realidad como objeto anímico y el repliegue a la intimidad como dos buenos ejemplos de estas calas de su producción textual, no queremos dejar de señalar estos signos visibles del voluntarismo estético del escritor alicantino. Solo así puede entenderse que la clave a la hora de descender a cualquier historial literario, y Alonso Ruiz no es una excepción, reside en poner de relieve esos principios doctrinales (Bohigas, 1963: 13) que exigen una continuidad (Piera, 1993: 36) con independencia de la estética, el tema o el momento de producción. Aunque, bien mirado, no debe confundirse soledad con intimidad; dos términos que -aún siendo ambos territorios radicalmente históricos donde se reproduce la servidumbre de la literatura- parecen intercambiables pero que, debido a las variaciones referenciales que sufren los referidos topoi literarios a lo largo de su historial, veremos alejados entre sí. Por ejemplo, un poema como "Hombre en la calle" puede ser una buena piedra de toque para reflejar tanto estos como otros matices. Próximo a la apertura pagana que se inicia con Soledad de alma (2001), incorpora el espacio urbano como un medio de cuestionamiento de su propio voluntarismo estético, como un medio de cuestionamiento de su propio proyecto ético-estético. Así, 
gracias a la ciudad, el escritor se replantea su vitalismo poético de tal manera que donde hubo grito y súplica (Acento humano), palabra sobre el lánguido tiempo (Testimonio de tiempo) ahora vira hacia una serenidad emocional (Soledad de alma), hacia la madurez (Cuaderno de ahora mismo).

De algún modo, aquella lección del Modernismo mediante la cual se rechaza la sociedad contemporánea y sus "valores científicos, financieros y fabriles" (Carnero, 1985: 92) sirve al poeta alicantino para saberse construir ese yo-poético inmerso en un refugio, esa torre de marfil que le permite juzgar el mundo estando-fuera-del-mundo: más allá del discurso. De ahí que hayamos querido diferenciar entre soledad e intimidad, puesto que si esta es la conquista necesaria de su realidad como objeto anímico, no es menos verdad que la palabra soledad -como bien señala Rafael Lapesa (1988: 243) en el caso de Bécquer- apenas aparece en su historial literario aún siendo uno de los leitmotiv de su clima poético. Porque, a fin de cuentas, aquello que sostiene las diferentes lecturas de aquellos topoi literarios de los que nos ocupamos, así como de los diferentes momentos de su producción textual, es la continuidad (Piera, 1993: 36) de ese señuelo del estilo que conceptualizado ya como libro de la vidaposee su máxima expresión en el voluntarismo estético.

Por ejemplo, si tomamos como muestra Cuaderno de ahora mismo (2012), uno de sus últimos poemarios, nos daremos de bruces con una línea poética que insiste en el vitalismo poético. La composición más relevante, en este sentido, es "Vivir": "Saber sentir el paso de la hora, / notar y conocer cualquier segundo, / padecer y gozar lo que es un mundo, / cantar y reír mientras se llora" (Ruiz, 2012: 32). Desde luego, y al albor de lo dicho hasta el momento, es significativa la distinción entre padecer y gozar el mundo frente a padecer y gozar un mundo. Nuevamente, se respiran en la tensión poética alonsiana conceptos como intimidad, estilo, impostura y ficcionalidad; términos todos ellos que remiten a la fantasmagoría subjetivista. Porque ya no se trata de literaturalizar la vida, vivir la poesía para escribir la vida, sino de la ilusión que empuja al escritor hacia la imposibilidad de la escritura; o como dice un verso, más adelante, del mismo poema: "querer el mismo afán que nos devora". Y aquí entra en juego la funcionalidad positiva y el valor ritual de la poesía (Arlandis, 2016: 280), ya que el gran aprendizaje que saca en claro el poeta es igualar en un mismo punto la imposibilidad de la literatura en tanto en cuanto es imposible la vida. O dicho de otro modo, en la misma balanza se sostienen el voluntarismo estético y la condicionalidad de la existencia humana: de la servidumbre de la vida a la servidumbre de la literatura.

\section{A MODO DE CONCLUSIÓN}

$\mathrm{Y}$ esta ambivalencia escenifica el firme compromiso con la construcción de un proyecto ético-estético: la construcción del libro de la vida, la representación de su libro de la vida. Aquí se halla ese voluntarismo estético, esa imposibilidad de "mi salvaje afán desesperado", que no se quiebra pese a las dificultades: desde la angustia existencial de Acento humano, el dolor ante la muerte de Testimonio de tiempo y Soledad de alma, pasando por los años de militancia en el MCPV (Moviment Comunista del País Valencià) y el Partido Comunista hasta llegar a la enfermedad reflejada en un ciclo de poemas dispersos. El historial literario de Francisco Alonso Ruiz, la representación de ese libro de la vida, es una sesuda edificación que no tolera una lectura lineal- 
evolucionista como tampoco una interpretación vaga de los consabidos topoi. Sino que en todo caso esa redundancia es intencionada puesto que sostiene la (re)creación de un clima poético donde el poeta alcanza la plenitud de su proyecto ético-estético: el repliegue a la intimidad mediante la realidad como objeto anímico. Y que, además, tanto la lluvia, la sombra, la muerte, el silencio y el día/tarde/noche responden en cada caso concreto -en cada texto- a un momento determinado de producción relacionado con el mismo arquetipo en otro texto y momento de producción distinto. Así que, y nos sacudimos nuevamente los fantasmas del pleonasmo, se trata del valor metafórico global de toda una producción poética leída en su conjunto y mediante los topoi referidos. De tal manera que no solo tendríamos aquello que Fontanier denomina -y que Lázaro Carreter aproxima en ciertas ocasiones a la sinonimia- como metábola, sino que este laberinto de espejos llama, únicamente, a esa puerta de la soledad del hombre. E invocamos la "idea de lenguaje" de forma "inseparable de la idea de referencialidad" (Piera, 1993: 33) cuando señalamos que, ya sea unas veces mediante una función simbólica y otras mediante una función irracional, esa realidad plural, imprecisa y de difícil determinación que es el expresado simbólico (Bousoño, 1979: 77) arropa la conceptualización de su libro de la vida: la escenificación de un andamiaje asociativo en el que cada arquetipo literario responde a una coherencia continuada (Piera, 1993: 36). De algún modo, ese tema encubierto que sobrevuela la obra alonsiana reclama esa coherencia interpretativa puesta en juego por el lector y que conocemos como isotopía (Eco, 1979: 131).

Porque si consideramos como isotopía "un conjunto de categorías semánticas redundantes que permiten la lectura uniforme de una historia" (Greimas, 1970: 188), qué mejor recurso a la hora de construir un perímetro lírico acotado por un sistema referencial, allí donde sean cuales fueren las variables de la lógica interna de producción siempre responden a un mismo trasunto. Al cabo, estos topoi literarios forman parte de esa gran metáfora que construye la producción textual de Alonso Ruiz vista en su totalidad y, además, deben entenderse tal y como Rascente (2011) observa agudamente en la propuesta topológica de la metáfora en Paul Celan- como puntos de intersección o lugares de encuentro. En todo caso, esa es la gran conquista en la poesía de Francisco Alonso Ruiz: la representación de una intimidad mediante el cristal del objeto anímico de la realidad. "Siempre supe que existe algo de olvido / en aquello que solemos llamar tiempo, / que es una habitación cualquier silencio / y una puerta cerrada lo vivido" (Ruiz, 2012: 18). La vida. La literatura. Cualquier hombre ya sabe de la herida / que abre su corazón cada mañana (Ruiz, 2012: 18).

\section{BIBLIOGRAFÍA}

- Arlandis, S. (2016). Revelación sombría: las oscuras calas de la escritura en la poesía de Francisco Brines. Anales de la Real Academia de Cultura Valenciana, 91, 273-306.

- Barthes, R. (2005). El grado cero de la escritura seguido de Nuevos Ensayos críticos. Madrid: Siglo XXI.

- Blanchot, M. (1969). El espacio literario. Buenos Aires: Paidós.

- Bohigas, P. (1963). Metafísica y retórica en la obra de Ausiàs March. Revista Valenciana de Filología, VI, 9-31.

- Bourdieu, P. (2005). El racismo de la inteligencia. Archipiélago, 66, 45-48.

- Bousoño, C. (1979). Superrealismo poético y simbolización. Madrid: Gredos.

- Carnero, G. (1985). Salvador Rueda: teoría y práctica del Modernismo. Anales de Literatura Española, 4, 67-96.

- Derrida, J. (1989). La escritura y la diferencia. Barcelona: 


\section{Cultura de los Cuidados}

Anthropos.

- Eagleton, T. (2013). El acontecimiento de la literatura. Barcelona: Península.

- Eco, U. (1979). Lector in fabula. La cooperación interpretativa en el texto narrativo. Barcelona: Lumen. 1993, 3. ${ }^{\text {a }}$ ed.

- Foucault, M. (1971). Las palabras y las cosas. Una arqueología de las ciencias humanas. México: Siglo XXI.

- Friedrich, H. (1974). Estructura de la lírica moderna. De Baudelaire hasta nuestros días. Barcelona: Seix Barral.

- Greimas, A. J. (1970). Du Sens. París: Seuil.

- Heidegger, M. (2009). Ser y tiempo. Barcelona: Trotta.

- Jakobson, R. (1983). Lingüística y poética. Madrid: Cátedra.

- Kristeva, J. (1978). Semiótica 1. Madrid: Espiral. 2001, 4..$^{\text {a }}$ ed.

- Lafont, C. (1993). La razón como lenguaje. Una revisión del giro lingüístico en la filosofía del lenguaje alemana. Madrid: Visor.

- Lapesa, R. (1988). Tres poetas ante la soledad. En De Ayala a Ayala. Estudios literarios y estilísticos (pp. 243272). Madrid: Istmo.

- Lukács, G. (1970). Arte auténtico y realismo. En Adolfo Sánchez Vázquez, Estética y marxismo, II (pp. 48-58). México: Era.

- - (1975). Teoría de la novela. Obras completas, vol. I (pp. 277-420). Barcelona: Grijalbo.

- Macherey, P. (1974). Para una teoría de la producción literaria. Caracas: Universidad Central de Venezuela.

- Mayos, G. (1995). Creatividad y subversión en el lenguaje. Analecta Malacitana, XVIII, 1, 117-126.

- Piera, C. (1993). Contrariedades del sujeto: Madrid: Visor.

- Plejanov, Y. (1974). Arte y vida social. Barcelona: Fontamara.

- Rascente, M. (2011). Metaphora absurda. Linguaggio e realtà in Paul Celan. Milano: Franco Angeli.

- Rodríguez, J. C. (1973). Ideología y lingüística (de Saussure a Chomsky). Gaceta Literaria, 1, 9-64.
- - (1974). Teoría e historia de la producción ideológica. Madrid: Akal.

- - (1994). La poesía, la música y el silencio. (De Mallarmé a Wittgenstein). Sevilla: Renacimiento.

- Rodríguez, J. C. y Salvador, Á. (1987). Introducción al estudio de la literatura hispanoamericana. Madrid: Akal. 2005, 3. $\cdot^{\mathrm{a}}$ ed.

- Ruiz Pérez, F. A. (1969). Acento humano. Alicante: plaquette autoeditada.

- - (1982). Testimonio de tiempo. Alicante: Publicaciones de la Caja de Ahorros Provincial de Alicante.

- - (2001). Soledad de alma. Elche: Colección Lunara.

- - (2009). "El libro". En Con diVERSOS acentos. Poemas Aucanos. Primera antología (pp. 30-31). Alicante: Asociación Cultural Auca de las Letras.

- - (2012). Cuaderno de ahora mismo. Alicante: Asociación Auca de las Letras.

- - (2015). Cosas terribles. AUCA. Revista Literaria y Artística, 35, 30.

- Salinas, P. (1970). Literatura Española Siglo XX. Madrid: Alianza.

- Steiner, G. (1982). Lenguaje y silencio. Barcelona: Gedisa.

- Valero Gómez, M. (2012). Cuaderno de ahora mismo: hacia la última poesía de Francisco Alonso Ruiz. AUCA. Revista Literaria y Artística, 25, 8-9.

- - (2013), El tiempo de los héroes. Cuatro poetas alicantinos. Alicante: Aguaclara.

- - (2018), El grupo de «Intimidad Poética». Primera promoción poética de la posguerra alicantina. III Premio Ensayo Certamen Literario María Zambrano UNED. Málaga: El Toro Celeste/ Fundación Unicaja/UNED Málaga.

- Valéry, P. (1990). Teoría poética y estética. Madrid: Visor.

- Wahnón, S. (1995). Lenguaje y literatura. Barcelona: Octaedro. 